\title{
Pensando el Dibujo: esquemática para la Figura Humana.
}

\author{
José Ignacio León Luque \\ Pontificia Universidad Católica de Chile \\ joseleon@uc.cl \\ Artículo bajo licencia Creative Commons \\ Atribución 4.0 Internacional (CC BY 4.0) \\ ENVIADO: 2020-03-30 \\ ACEPTADO: 2020-09-02
}

\section{RESUMEN}

El argumento se presenta considerando la práctica y reflexión sobre el acto de dibujar, específicamente en función de comprender y representar la Figura Humana observada o imaginada. Se desarrolla y propone un esquema volumétrico para el Tronco o Torso, estableciendo posibilidades visuales para las posturas y gestos del cuerpo en el espacio a partir de tipologías características, tales como Simetría vertical, Flexión, Torsión y Flexo/ Torsión. El material se ha elaborado y organizado otorgando especial relevancia a la comunicación visual del fenómeno para la comprensión y representación de la Figura Humana, considerando promover especialmente el ejercicio y estudio expresivo de la imaginación mediante el dibujo de memoria y la interpretación/representación a partir de la imagen impresa o digital y del modelo vivo.

PALABRAS CLAVE

Cuerpo; dibujo; empatía; esquema; punto de vista.

\section{RESUMO}

O argumento é apresentado considerando a prática e a teoria do desenho, especificamente para a adequada compreensão e representação da Figura Humana que é observada e / ou imaginada. Um esquema volumétrico é desenvolvido e proposto para o Frustum ou Torso, estabelecendo possibilidades visuais para as posturas e gestos do corpo no espaço, com base em tipologias posicionais, como Simetria Vertical, Flexão, Torção e Flex / Torção. 0 material foi elaborado e organizado, dando especial relevância à comunicação visual do fenômeno, para a compreensão e representação da Figura Humana, principalmente considerando a promoção do estudo e exercício expressivos da imaginação através do desenho da memória e da interpretação / representação a partir de uma imagem impressa ou digital e o modelo vivo.

Palabras Clave

Corpo; desenhando; empatia; esquema; ponto de vista.

\section{ABSTRACT}

The argument is presented considering the practice and theory on drawing, specifically for the adequate comprehension and representation of the Human Figure that is observed and/or imagined. A volumetric scheme is developed and proposed for the Frustum or Torso, stablishing visual possibilities for the postures and gestures of the body in the space, based on positional typologies, such as Vertical Symmetry, Flexion, Torsion and Flex/Torsion. The material has been elaborated and organized giving special relevance to the visual communication of the phenomenon, for the comprehension and representation of the Human Figure, especially considering promoting the expressive study and exercise of the imagination through memory drawing and the interpretation/representation starting from a printed or digital image and the living model.

\section{KEYWORDS}

Body; drawing; empathy; scheme; point of view. 


\section{INTRODUCCIÓN}

Este ensayo se propone como una posibilidad de estudio, ejercitación y comprensión, para abordar la complejidad de la representación de la figura humana en un sentido volumétrico y espacial, concentrando la observación atenta y la imaginación intuitiva justamente en la simplificación del fenómeno. Pondremos especial atención en un asunto que consideramos fundamental para la observación y comprensión de la postura en términos volumétrico espaciales: el Tronco o Torso, sus tramos característicos (Caja Torácica, Abdomen y Caderas ${ }^{1}$ ) y sus interacciones en tanto sistema tridimensional dinámico y estructural para la Figura Humana. Propondremos diferentes volúmenes articulados que podrían configurar esta estructura, para aproximarnos a la representación que nos ofrece este sistema más allá de su aspecto descarnado, y, paradójicamente, valiéndose de ello para una comprensión de la Figura Humana como cuerpo volumétrico estructural en el espacio. Plantearemos también la cuestión para pensar y valorar el Dibujo en relación con su sentido y funcionalidad.

Situaremos en segundo lugar el asunto que refiere a las extremidades para la representación de la Figura Humana -que para efecto de lo que pretendemos quedará abierto-, comprendiendo, no obstante, que las extremidades son esenciales en la situación postural y gestual del cuerpo. Esto lo decimos refiriéndonos a la gestión de las tensiones, los apoyos y el equilibrio, manifestaciones estas de un estado interior o de una solicitación específica interna o externa, consciente o inconsciente, que confluyen en una postura y gestualidad. Entonces y en términos generales diremos que, en tanto sistema dinámico complejo compuesto, la postura y gestualidad en la Figura Humana resulta de las tensiones que en determinadas situaciones confluyen y/o provocan las variaciones y compensaciones en este sistema corpóreo general y que expresan o se expresan en una postura determinada; y que, para efectos de este análisis, nos concentraremos especialmente en la visualización del Tronco como acontecimiento postural.

Considerados en su mecánica y desprovistos de lo estético, este sistema de volúmenes imaginado, proyectado, observado y contrastado con la realidad, posibilitaría comprensiones para las funciones posturales y gestuales del cuerpo humano. Asuntos estos que deberían ser perseguidos y buscados inquisitivamente por el dibujante para alcanzar su expresión, poniendo en relieve principalmente que, en tanto cuerpo, la Figura Humana es un sistema que ocupa, se sitúa, usa, define e involucra espacio. Concentraremos particularmente la atención, como hemos dicho, en el Tronco en tanto conexión y estructura clave para una comprensión y representación general de la Figura Humana. 


\section{REPRESENTACIÓN/TRADUCCIÓN/INTERPRETACIÓN}

El problema general de la representación mediante dibujo, cuyo motivo pertenezca a "lo que está ahr", fuera de nosotros o si se quiere, externo al sujeto, radica en términos simples y fundamentales en las interpretaciones dimensionales y sus consiguientes traducciones a códigos gráficos. A las correspondencias y relaciones que se construyan entre una y otra dimensión, entre una y otra realidad, en tanto nexos o puentes para establecer, estudiar, develar y proponer coherencias que nos permitan construir y visualizar comprensiones sobre el fenómeno de estudio. Así, simplificamos el problema dimensional del dibujo refiriéndonos de modo simple al traspaso desde las tres a las dos dimensiones (3D y 2D), a una suerte de copia analógica que se limitaría a una traducción. Pero si solamente se tratase de esto, estaríamos olvidando una dimensión circunstancial contenida en la duración o temporalidad del proceso, cuya construcción requiere y solicita de momentos y atenciones diferidas que son afectadas por exterioridades de diversa naturaleza, en las cuales se ve inmerso el dibujante y que, por lo tanto, implican su subjetividad y naturaleza individual afectiva. Entonces, desde este punto de vista "lo que está ahî" involucra al dibujante provocando su participación, solicitando un grado de empatía con la cual se pueda trabajar y producir cierta correspondencia o reconocimiento, como correlato entre realidad, exterioridad/interioridad e individualidad. Lo que contiene el cuerpo otro apreciado desde el cuerpo propio. Sus implicancias posturales, gestuales y gravitacionales sentidas, traducidas, expresadas, observadas y/o imaginadas en códigos gráficos gesticulados, balbuceados; articulados en un lenguaje gráfico que confluye en una interpretación mediada por el dibujante intérprete. Desde un cuerpo sensible que busca comprender y visualizar, que se expresa mediador, mediante una performance que vincula afectivamente al objeto con el sujeto en la transcripción y transferencia producto particular de esta práctica.

Así, planteamos la simplificación volumétrica como una forma de comprender la Figura Humana en tanto cuerpo en el espacio, tipificando sus deformaciones posturales y gestuales, relacionando el fenómeno con el punto de vista desde el cual se sitúa y se pregunta el observador. Y justamente porque pensamos que ello puede ocurrir como sistema y responder a un conjunto de posibilidades perspectivo espaciales, es que consideramos el asunto abierto a la exploración o experimentación sin sujeciones a un modelo o modo de dibujar cerrado. Se trataría más bien, de una guía o delineación de asuntos sobre los cuales poner especial atención para una iniciación sobre apreciaciones más "finas" para la observación y estudio del cuerpo en contexto espacial, contrastado con la experiencia que se va construyendo en y por la práctica. Intentaremos entonces, definir un esquema simplificado y desglosar las partes constitutivas para luego integrarlas y dar cuenta de un repertorio general de posibilidades de comportamiento para las posturas corporales. Lo que sigue, obviamente, sería la reflexión y práctica sensible, empática e intuitiva mediante el dibujo.

Por lo tanto, como hipótesis general, establecemos una relación entre lo que "se ve y entiende" respecto de la traducción a códigos gráficos producto de la acción del dibujar. Más específicamente, planteamos que la relación entre lo que se ve o lo que se elige mirar respecto de su traducción e interpretación a códigos gráficos como producto de la acción de dibujar, estaría directamente relacionada con las comprensiones y búsquedas que persigue el individuo en la acción de dibujar.

\section{Algunos Antecedentes}

A continuación, haremos una referencia a esquemas que podemos revisar en bibliografía destinada al dibujo de la Figura Humana y a modelos diseñados para emular y referenciar posturas y gestos corporales. Nuestra reflexión respecto de estos últimos es en general crítica, en tanto restringen la comprensión y por lo tanto la representación a las posibilidades que ofrece su aspecto y aún más importante, su "anatomía”.

Comenzando por los llamados figurines de madera disponibles hoy en el mercado, podemos apreciar que su aspecto en referencia al cuerpo humano está distorsionado por las formas que los definen, particularmente, en lo relativo a la cabeza, tronco y pies, haciendo que en algunas de estas zonas sea difícil distinguir la parte delantera de la trasera (cabeza y caderas), o, distorsionando su relación anatómica de referencia (proporción entre pie y talón). Más problemático aún resulta la movilidad restringida de este modelo, pues entorpece la emulación de la gestualidad postural del cuerpo humano. Porque, para qué serviría un modelo de este tipo sino es para posibilitar el juego y manipulación de su conjunto en aras de potenciar comprensiones sobre su referente. Lo cierto es que este tipo de figuras resulta finalmente ser un componente inútil que acompaña en el ámbito de las especulaciones los artículos de un taller - laboratorio artístico, cuya funcionalidad distorsionada sólo ofrece la promesa de un modelo para el estudio resultando torpe en su manipulación. Si lo que decimos es cierto, ¿cómo podría aportar un modelo tal a la comprensión y representación de la Figura Humana?

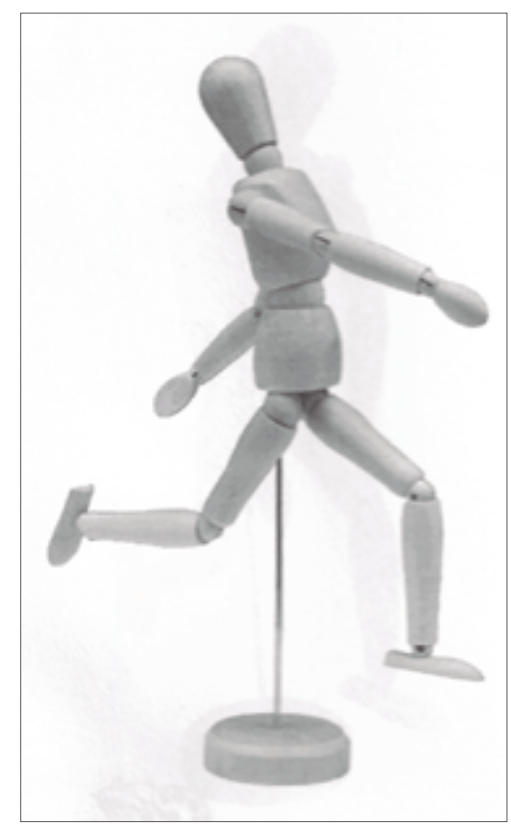

Imagen. $\mathrm{A}^{2}$

Borges, 2016: 136 
Una sutileza respecto de las posibilidades gestuales en este tipo de modelos, es lo que se puede apreciar en la imagen del figurín que aparece en el libro de José María Parramón (Parramón, 1973: 27), pues su abstracción, así como las soluciones formales para las articulaciones y extremidades permitirían jugar y encontrar posturas cuya referencialidad a la figura humana resultan, en las imágenes expuestas en el texto, más naturales o acordes con lo que el cuerpo humano es capaz de realizar en tanto postura y gestualidad, sobre todo, lo que dice relación con la flexión y torsión del tronco y su consecuente implicancia con el resto del sistema corporal.

También parece interesante el modelo que podemos apreciar en este texto de Parramón, compuesto por alambre y papel. Con una abstracción simple a modo de cáscara y una estructura de alambre a modo esqueleto, constituye una invitación a explorar posturas y gestos que cumplan de mejor manera la función para emular la gestualidad de la Figura Humana.

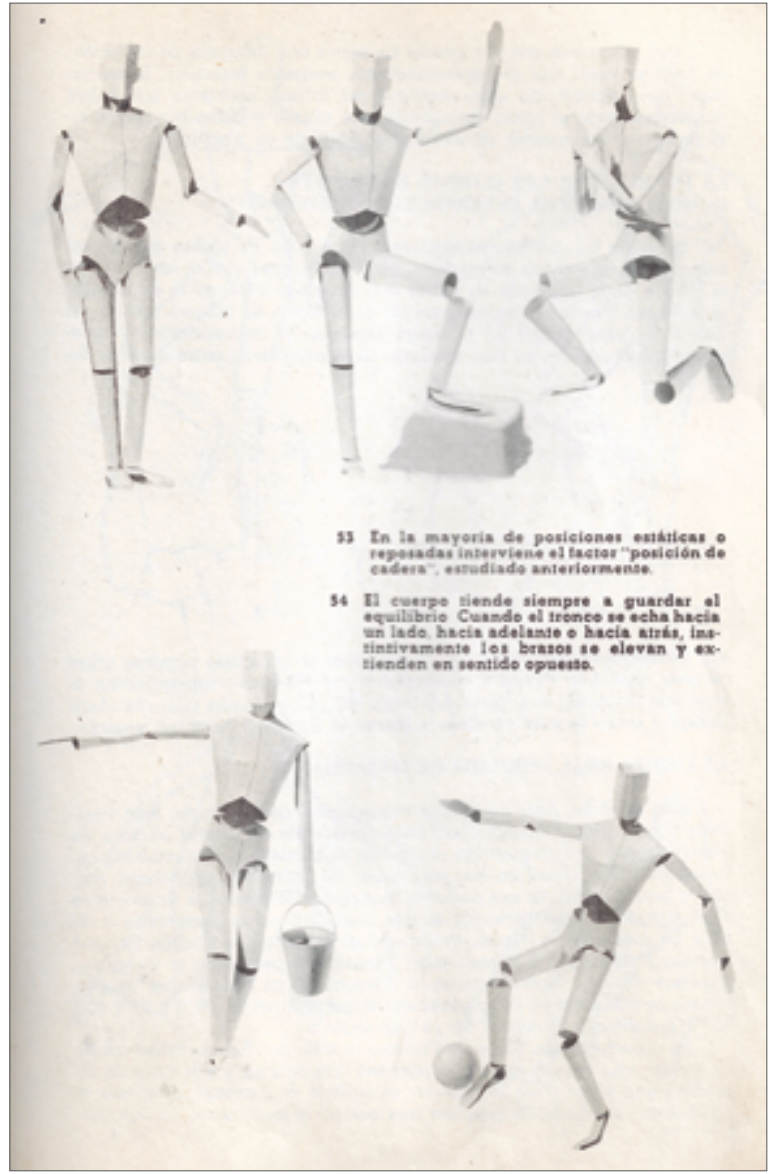

Imagen. $B^{3}$

Respecto de los ejemplos revisados de modelos gráficos simplificados, se aprecia una elasticidad gestual y una mayor posibilidad de expresión, probablemente porque involucran la imaginación y ciertas comprensiones y técnicas que en vez de restringir o limitar las posibilidades posturales y gestuales, colaboran en y con su conocimiento y expresión. En algunos de estos, la referencia a la anatomía es mayor, relacionando de esta forma una abstracción intermedia con aspectos directamente relacionados con el esqueleto (Barcsay, 1973). En otros, la simplificación es tal, que la figura se transforma en ejes lineales que, en sus mejores exponentes, expresan una ejercitación abierta y gestual de determinadas posturas dinámicas (Brambilla, 2015: 93). En otros casos, se reconoce el interés por relacionar la expresión de la figura en sus elementos o pares correspondientes (hombros, rodillas, manos, apoyos, etc.), relación que didácticamente se manifiesta con líneas auxiliares y en una correspondiente movilidad que permite comprender el comportamiento dinámico. Valoramos estas posibilidades y nos preguntamos acerca de la forma en que sin perderse en la exigencia de un modelo gráfico virtuoso que exija cierto conocimiento previo (esqueleto, anatomía), o en el cual su aspecto sea un factor de distracción de lo que consideramos estructuralmente relevante o fundamental, se pueda abordar de manera simplificada tanto las posibilidades dinámicas que ofrece la figura/volumen así como su disposición en el espacio respecto de un punto de vista.

De esta forma, más que la construcción de un modelo a escala, proponemos entonces la posibilidad de jugar gráfica y proporcionalmente con ciertos volúmenes relacionados en su función con el Tronco, entendido como concentración expresiva de la postura y gestualidad para la representación de la Figura Humana. Asunto determinado por las fuerzas que se ejerzan o produzcan en esa zona y/o mediante las extremidades, aún cuando planteemos las extremidades como secundarias para efectos de la simplificación del análisis. Como ya hemos señalado, entendemos cierta dependencia sistémica entre el tronco y las extremidades, pero también una cierta independencia que podría ser más o menos acorde para una misma postura y gestualidad específica generando posibilidades para diferentes versiones. Por ejemplo, la mano podría gesticular de diferentes maneras frente a una misma postura general, digamos erguida y flectada, o si se quiere, puede ser objeto de estudio aisladamente. No obstante, consideramos también que cierta gestualidad general o performance, se expresaría de una manera única conforme a un sujeto particular y en determinada circunstancia, es decir, a una escena particular y algún contexto histórico. Consideración que la arqueología estudia y aplica en la restauración a partir de torsos en tanto fragmento que perdura a la escultura de determinado período histórico o narrativa, por ejemplo. 


\section{HIPÓTESIS}

Si aceptamos que lo central para la representación de la Figura Humana entendida como sistema volumétrico dinámico, sería la comprensión de una abstracción esquemática ajustada a ese requerimiento que posibilite el estudio a partir del modelo vivo y la imaginación, como así también, desde la imagen gráfica impresa o digital, podremos establecer de manera general estas posibilidades para profundizar luego o conjuntamente en comprensiones y expresiones no menores relativas al equilibrio, apoyos, peso, tensiones, etcétera. En el caso de trabajar a partir de la imagen gráfica impresa o digital, pretendemos extraer de esta realidad plana la naturaleza corpórea y dinámica de origen, mediante una observación enfocada y una imaginación empática, para expresar sus dimensiones, cuestionando, atendiendo y rompiendo con la de-formación de la línea comprendida y aplicada en tanto traducción gráfica directa para el borde o silueta.

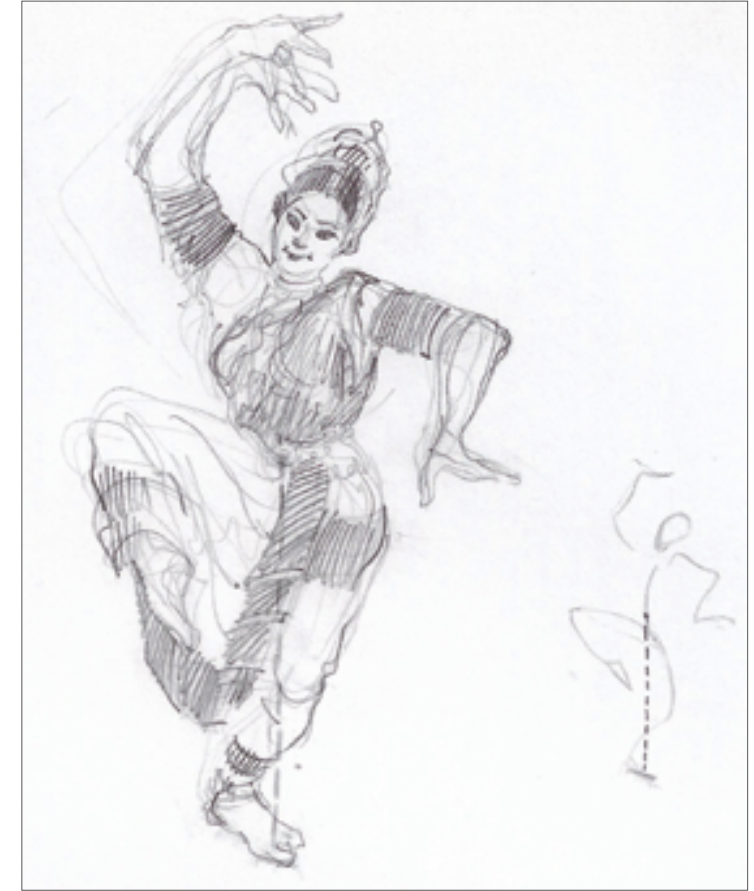

Imagen. $C^{4}$

Por lo tanto, las hipótesis que subyacen en nuestro análisis para este enfoque implican fundamentalmente cuatro asuntos:

a) El qué y cómo se observa o ve determina el para qué del dibujo, su función.

b) Que en el dibujar, práctica y reflexión se complementan para la comprensión y representación.

c) Que para el dibujar, consideramos relevante y directa la implicación atribuible al punto de vista subjetivo en su situación respecto de las deformaciones aparentes.

d) Que un vocabulario o categorización de las posibilidades de la figura humana como cuerpo en el espacio visto desde determinados puntos de vistas puede servir de guía para estudios y expresiones acerca de múltiples posibilidades posturales y gestuales.

Seguido de esto, consideramos también importante para la definición del esquema que proponemos, delimitar categorías posicionales para la Figura Humana (que presentaremos en posición erguida), a partir de volúmenes regulares que faciliten por pregnancia establecer con mayor facilidad su posición en el espacio y su comprensión tipificada en relación con las posibilidades de girar en torno al Tronco, de manera de relevar que la corporalidad en el espacio es un fenómeno dinámico que involucra visualmente siempre el escorzo. Sobre ello, queremos aclarar que no se trataría de someter la figura humana al sistema de representación perspectivo, sino valerse de este para comprender y aplicar lo implicado que está el punto de vista subjetivo en su situación respecto de las deformaciones aparentes. 


\section{EL ESQUEMA}

El concepto de estructura o de cierto andamiaje, refleja la necesidad de un esquema a partir del cual aproximarse al conocimiento de la relativa y aparente realidad. La forma esencial y su búsqueda como idea, provee entonces al artista de la capacidad de encontrar lo universal en lo particular, un eco platónico respecto de alcanzar constituyentes geométricos o abstracciones en la naturaleza (Gombrich, 1998: 133 - 147). Pero, cuál es su influencia, cómo condiciona la percepción. Para que la idea de esquema subsista en el lenguaje de la representación, consideramos que su contenido puede aplicarse a lo particular mediante adaptaciones. Así, la diferencia con una idea de esquema universal, es que el esquema aplicado en lo particular se someterá a constante revisión y corrección. Es un punto de partida desde donde se desarrollan las particularidades, las diferencias, como una posibilidad relativa que depende tanto del sujeto como del objeto en una condición y situación específica.

El esquema que a continuación describimos, consiste en aquella imagen y su desarrollo o secuencia, que da cuenta de un pensamiento cuyo objetivo es facilitar una comprensión máxima simplificada respecto de un problema complejo. En este caso, de interpretación y representación gráfica del cuerpo humano en un sentido volumétrico y espacial a partir de una atención específica en la zona del Tronco o Torso. Es importante hacer mención, que el esquema en tanto imagen funciona relacionando dos cuestiones: a partir de la observación y/o imaginación, considerando la experiencia y la posibilidad de una conexión empática, deviene una conjugación valorizada entre lo que se sabe y lo que se ve, proponiendo una abstracción y visualización perspectiva de volúmenes simples en correspondencia analógica con partes de la Figura Humana y sus cualidades de rigidez, flexibilidad y movilidad. Es decir, una imagen abstracta y volumétrica consecuente y comparable con cualidades observadas y/o imaginadas para la Figura Humana, cuya comprensión posibilitaría su interpretación y traducición a códigos gráficos desde un particular punto de vista.

De esta forma, se considera la siguiente correspondencia analógica:

1. Tórax = CAJA (Rígido); para efectos de este esquema no se considera la capacidad flexible del tórax.

2. Abdomen $=$ CILINDRO (Flexible)

3. Caderas $=$ CAJA (Rígido)

Además, consideramos especialmente la volumetría cilíndrica para la comprensión de la corporeidad asociada a la Figura Humana.

A nuestro juicio, lo relevante del esquema que proponemos es la detección y proposición de algunas claves que posibilitarían concentrar la atención sobre aspectos complejos simplificando sus interacciones y formas, provocando un dibujar en función de un objetivo causal sobre la posición y gestualidad del cuerpo humano en el espacio. Algo importante a tener presente para la ejercitación del dibujo, sería también la proporción que, para efecto de esta simplificación, consideramos respecto a una dimensión total y no a partir de la parte como tradicionalmente se ha hecho (Canon de 8 cabezas, por ejemplo). Así, si trazamos o imaginamos la altura total de la figura humana erguida, la mitad de esta dimensión la ubicaremos en el pubis (asunto que se puede observar en la mayoría de los cánones que emplea la cabeza como parte para proporcionar el todo). El resto de las partes las dimensionaremos en función expresiva considerando el escorzo, la observación, la experiencia producto de la práctica.

\section{DeSARROLLO del ARgumENTO VISUAL}

Presentamos a continuación una secuencia de 10 imágenes, en donde se desarrolla visualmente el esquema para comunicar las compresiones que proponemos alcanzar e incorporar, comenzando por la Ideación (Imágenes 1 y 2), Visualización (Imágenes 3, 4, 5 y 6) y finalmente Aplicación demostrativa (imágenes 7, 8, 9 y 10).

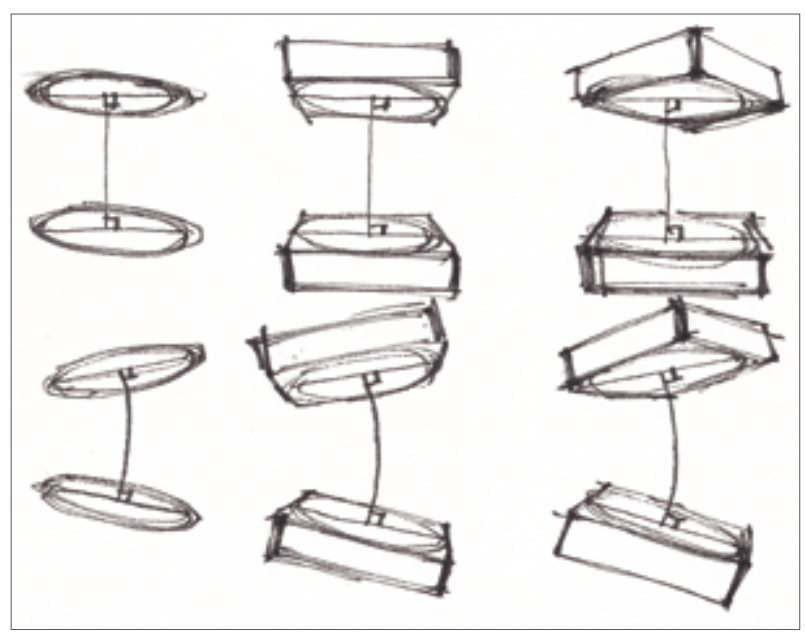

Imagen 1. Esbozo inicial para la construcción gráfica del diagrama del tronco, sus tipologías características y posibles posiciones. ${ }^{5}$

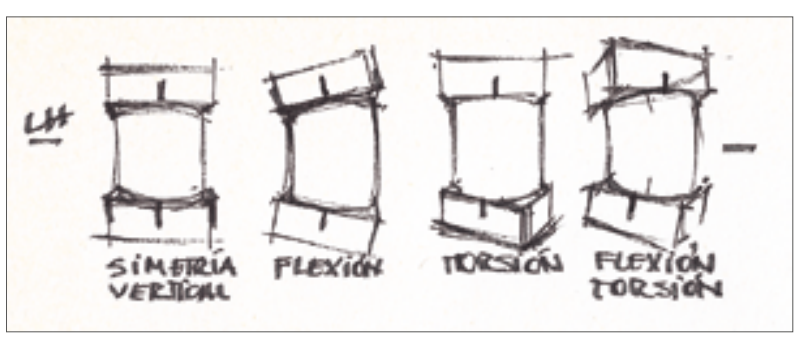

Imagen 2. Esbozo inicial para cuatro posiciones características desde altura de mirada a nivel medio del abdomen. ${ }^{6}$

De izquierda a derecha. Esbozo en Simetría Vertical (arriba) y Flexión (abajo), que relaciona eje mayor de las elipses perpendicularmente con el eje del cilindro virtual que las contiene. Esbozo en Simetría Vertical (arriba) y Flexión (abajo), que relaciona eje mayor de las elipses perpendicularmente con el eje del cilindro virtual que las contiene y la caja definida para el Tórax y Caderas. Esbozo en Torsión (arriba) y Flexo - Torsión (abajo), que relaciona eje mayor de las elipses perpendicularmente con el eje del cilindro virtual que las contiene y la caja definida para el Tórax y Caderas. Dibujos realizados por el autor con pluma caligráfica Pentel / tinta negra sobre papel

6 Dibujos realizados por el autor con pluma caligráfica Pentel / tinta negra sobre papel 


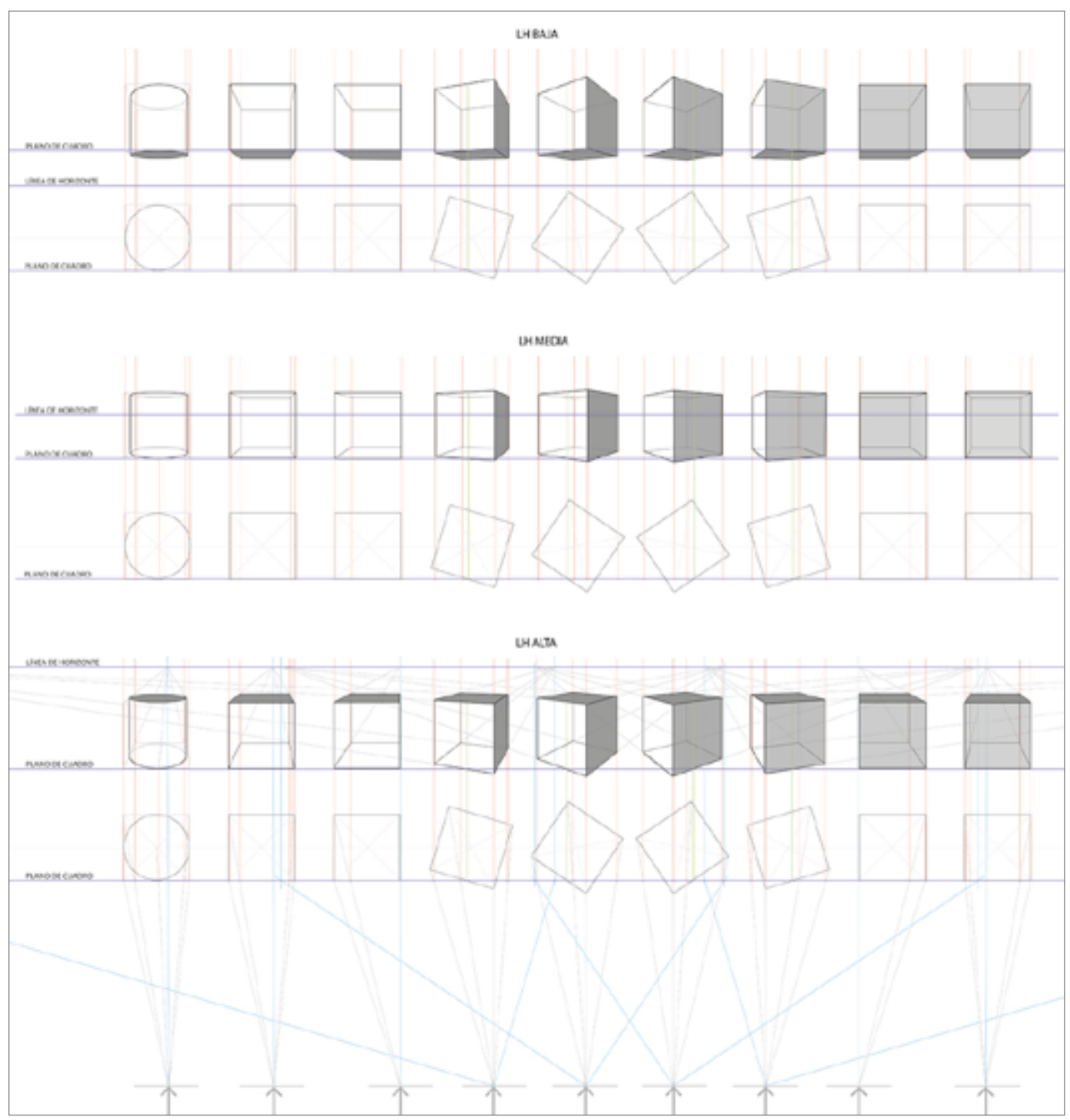

Imagen 3. Esquema desagregado. Construcción y visualización del cilindro y cubo para tres alturas de mirada desde puntos de vista en rotación. En orden decreciente: Línea de Horizonte baja, media y alta. ${ }^{7}$

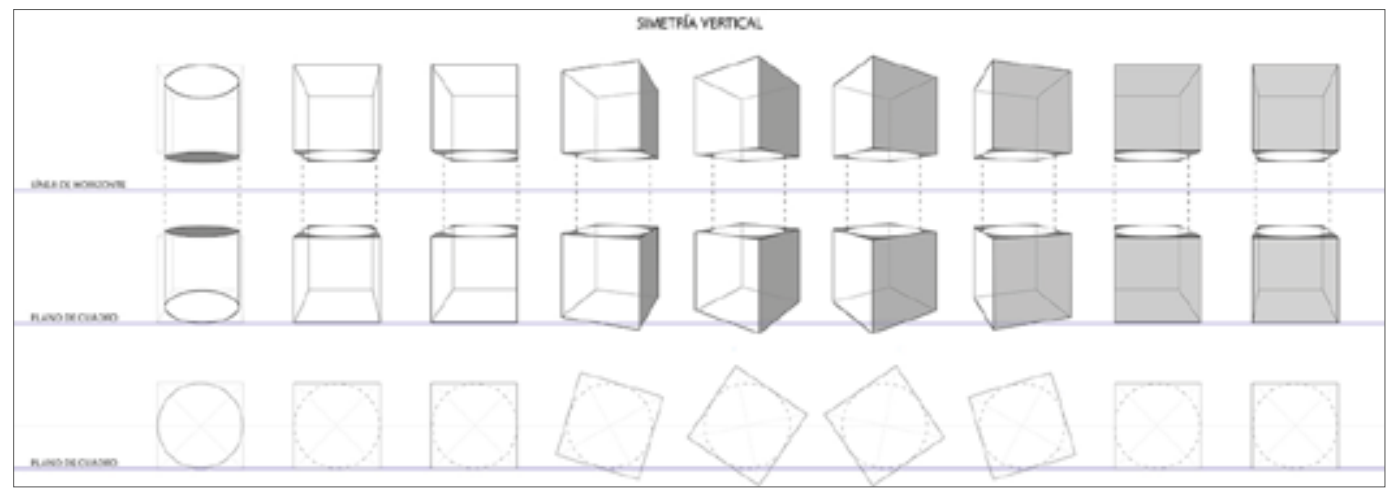

Imagen 4. Esquema integrado. Tipología para la posición del Tronco que hemos denominado "Simetría Vertical”, para una altura de mirada media respecto de puntos de vista en rotación. ${ }^{8}$ 


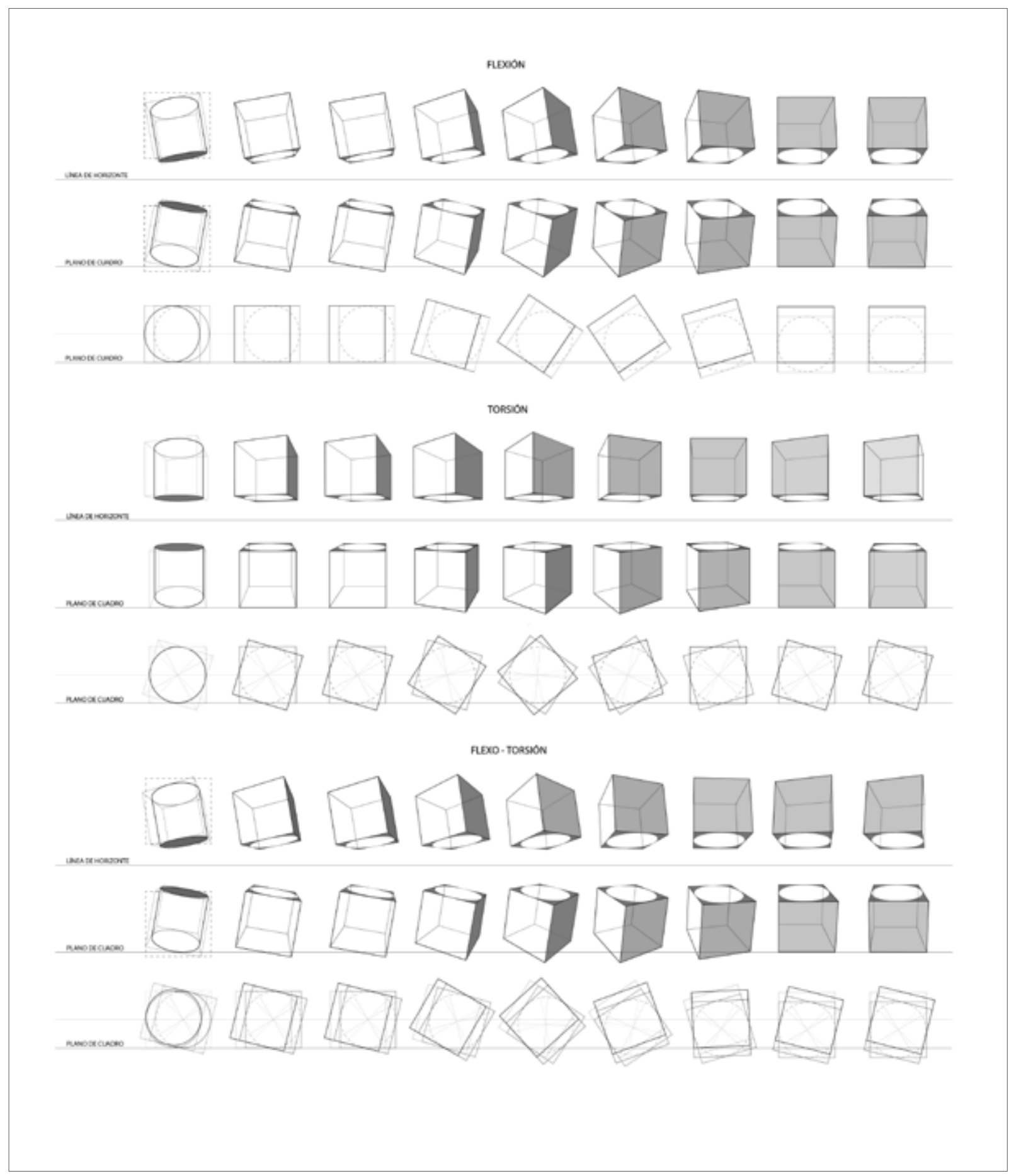

-Imagen 5. Esquema integrado. Tipologías para posiciones características del Tronco para una altura de mirada media respecto de puntos de vista en rotación. En orden decreciente: Flexión, Torsión y finalmente, Flexo-Torsión. En estas posiciones, el Abdomen/Cilindro no se ha dibujado dejando su interpretación abierta a la imaginación y empatía. ${ }^{9}$ 


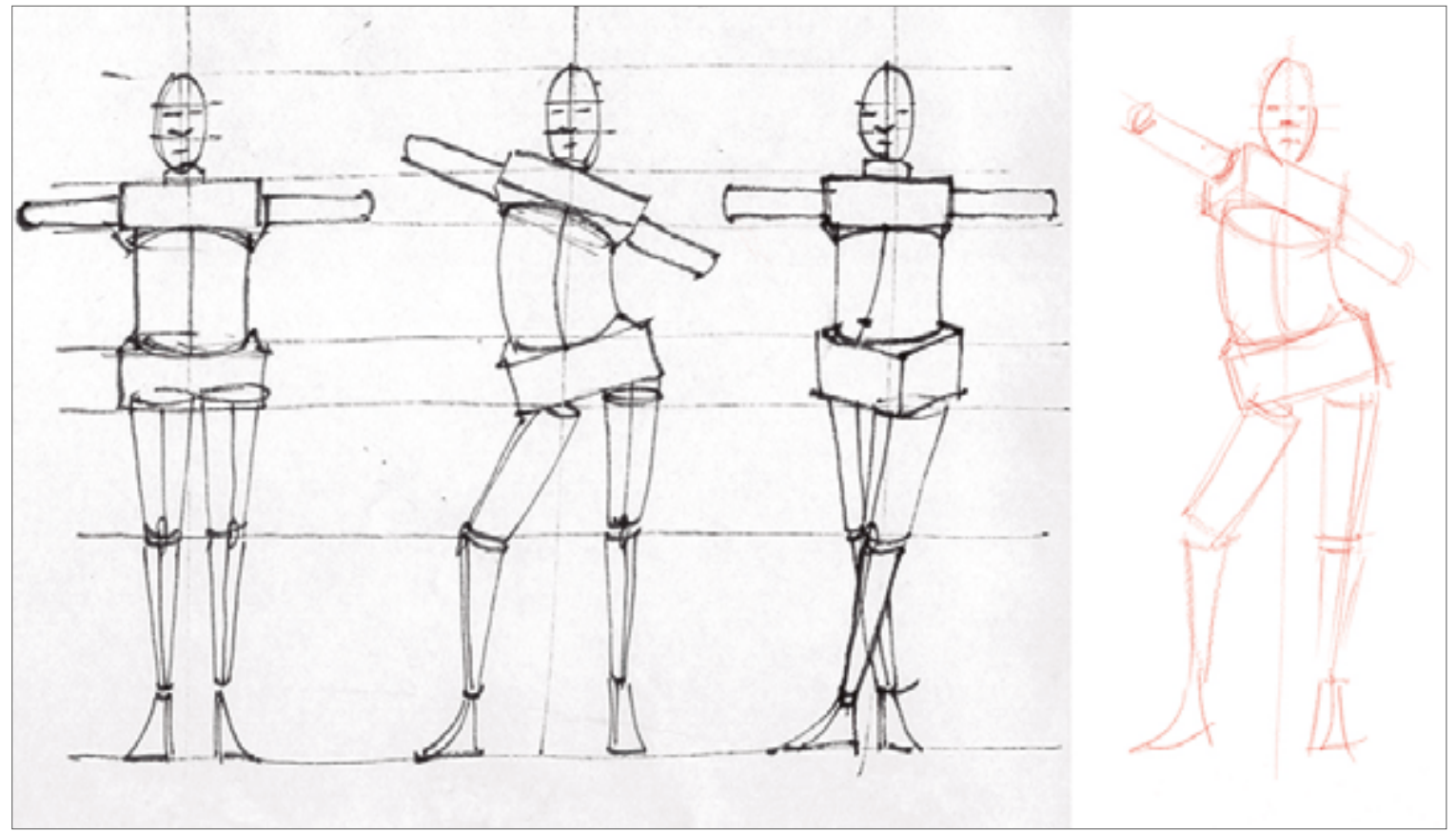

Imagen 6. Esbozos para esquema general aplicado y tipologías características para la posición erguida desde una mirada a la altura del abdomen. De derecha a izquierda: Simetría Vertical; Flexión, Torsión; Flexo/Torsión. ${ }^{10}$
Consideramos importante para el estudio, interpretación/representación y expresión gráfica de la posición y gestualidad de la Figura Humana en el espacio, tener presente lo que denominaremos Ley de compensación, ya que, al comprender la Figura Humana como sistema, hay que aceptar que las partes conforman el todo siendo interdependientes, en correspondencia y en simetría. Lo cual equivale a decir que, por ejemplo, si un lado del cuerpo se eleva, el otro baja; si hay elongación en una parte del cuerpo y por lo tanto tracción, en otra habrá acortamiento y por lo tanto compresión; si una parte se adelanta y ello compromete el equilibrio, la otra debe retraerse o el cuerpo hará algún movimiento compensatorio para reestablecer el equilibrio (Parramón, 1973). Asuntos que ocurren especialmente en posiciones que involucran flexión y torsión, y en situaciones dinámicas, como por ejemplo en el caminar. Ahora bien, afortunadamente el dibujar solicita, a la vez que otorga, ciertas licencias expresivas que no necesariamente son coincidentes con la medida, proporción y anatomía reales. Ello dentro de ciertos límites que cada dibujante que intenta comprender y expresar delimitará subjetiva e intuitivamente, asunto que consideramos puede medirse en términos de reconocimiento respecto de la experiencia de la realidad que todos tenemos incorporado a nuestra individualidad y que está en permanente construcción. 


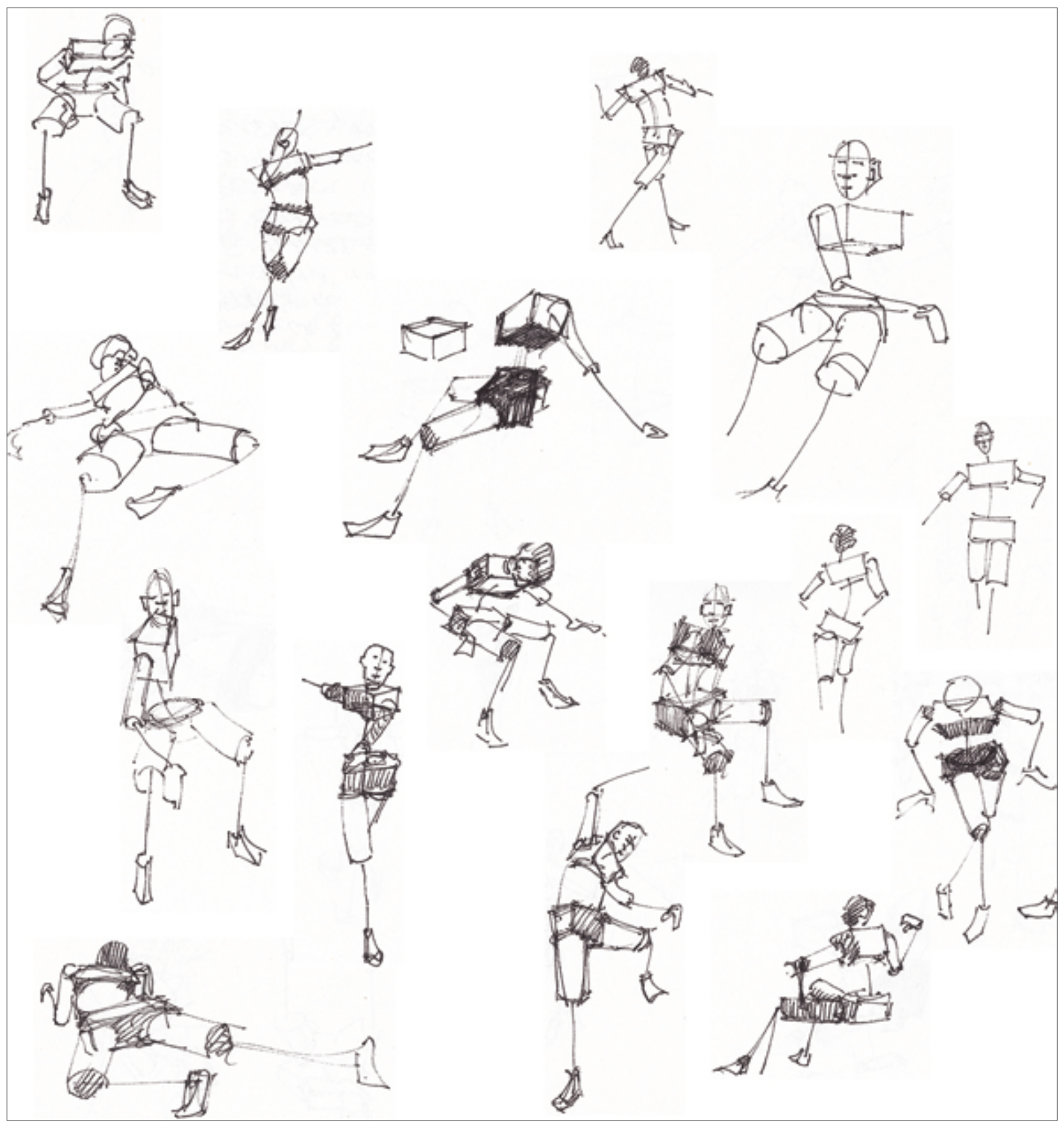

-Imagen 7. Estudios para ejercitar la memoria y el reconocimiento de la posición y gestualidad de la Figura Humana a partir de la aplicación del esquema volumétrico. ${ }^{11}$ 


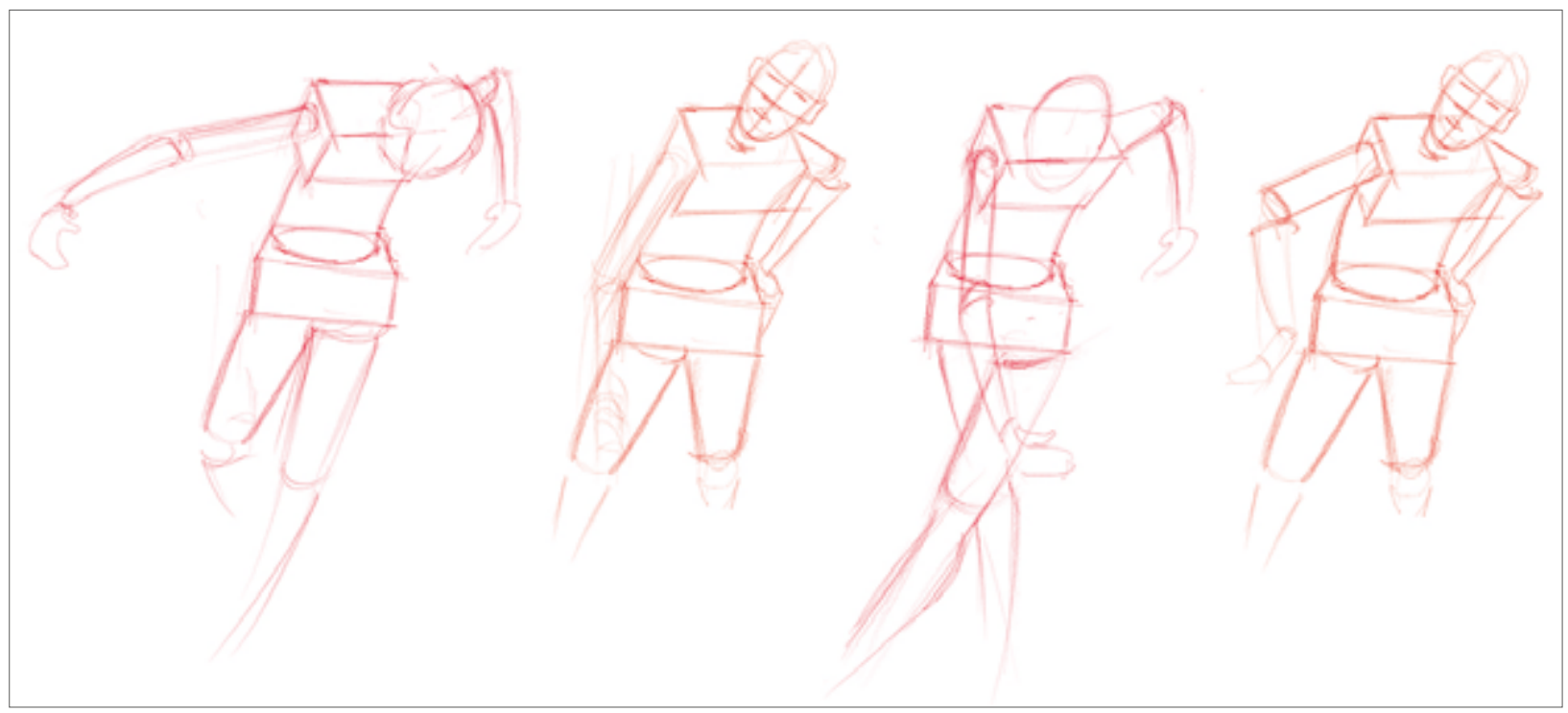

Imagen 8. Versiones. Estudios para ejercitar la memoria y el reconocimiento de variaciones gestuales posibles para una misma posición esquemática del Tronco en la Figura Humana. ${ }^{12}$

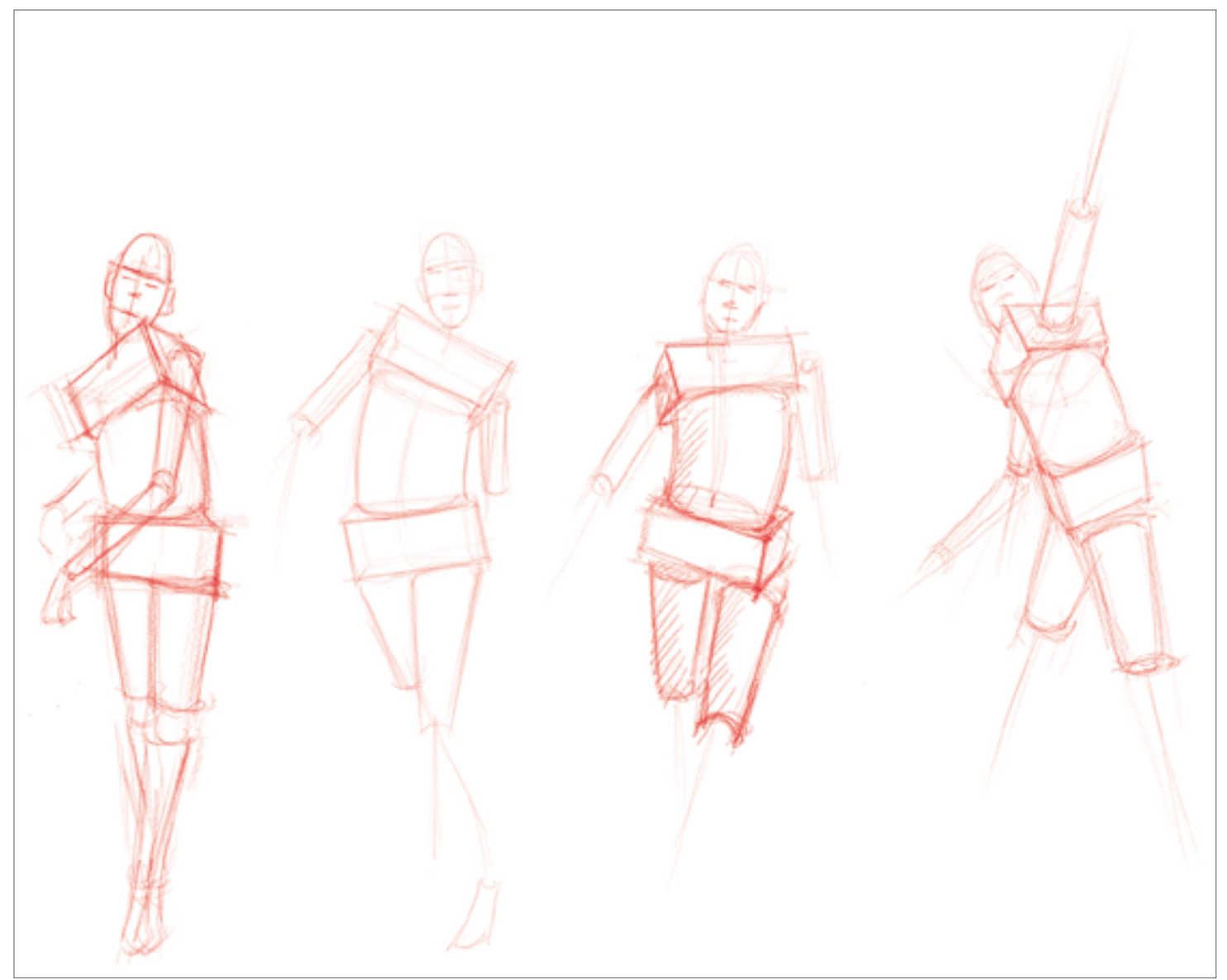

Imagen 9. Estudios para ejercitar la memoria y el reconocimiento de la posición y gestualidad de la Figura Humana a partir de la aplicación del esquema volumétrico. ${ }^{13}$ 


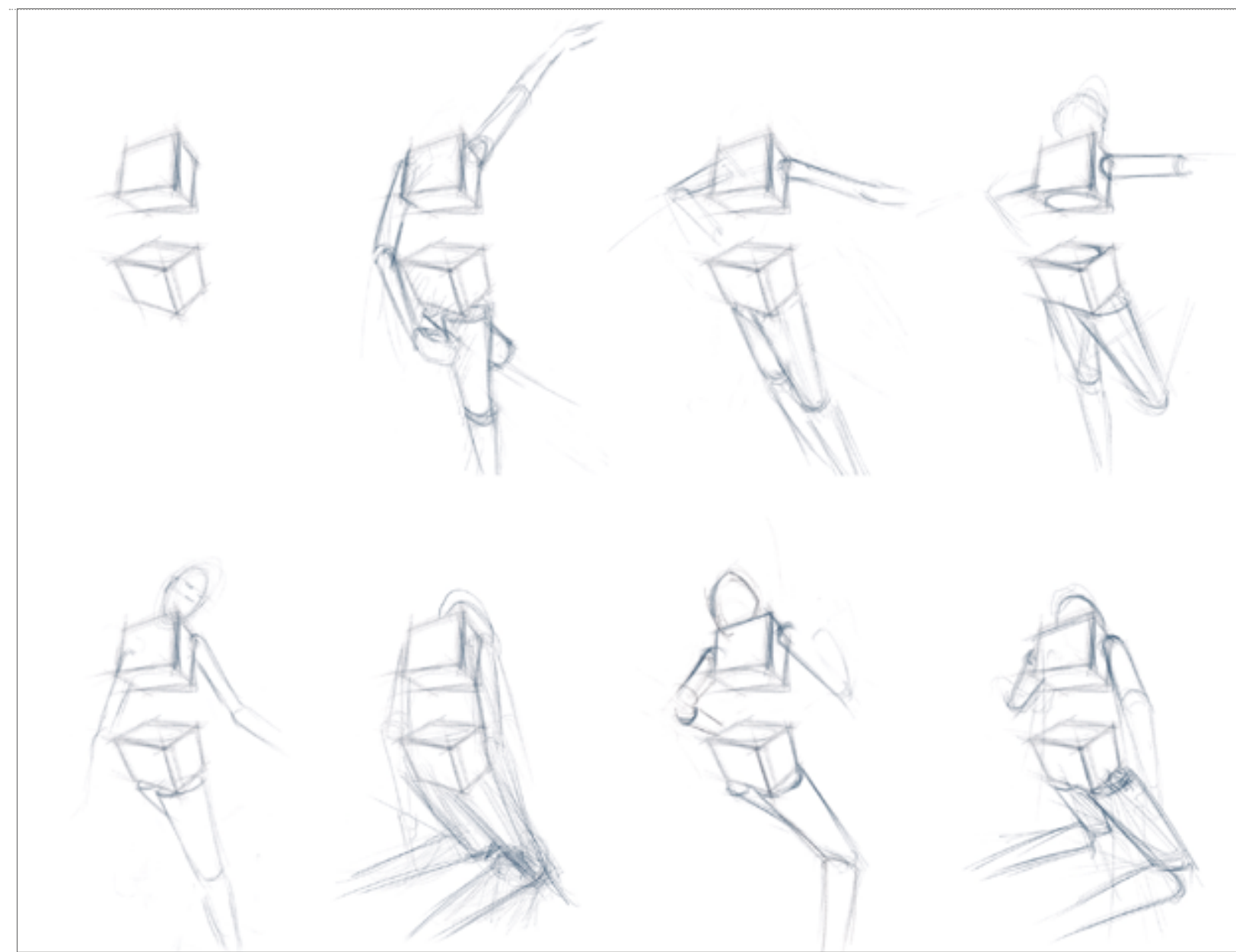

Imagen 10. Versiones y capas. Estudios para ejercitar la memoria y el reconocimiento de variaciones gestuales posibles para una misma posición esquemática del Tronco en la Figura Humana. Cada estudio se ha dibujado digitalmente manteniendo la primera capa activa. ${ }^{14}$

\section{El Dibujo COMO PROCESO POR CAPAS. Un EJERCICIO de EXPRESIÓN GRÁFICA Y DE DIBUJO SOBRE SOPORTE DIGITAL COMPARADO.}

Para el desarrollo de este ensayo y argumentación gráfica se ha dibujado a mano alzada utilizando medios de expresión tradicionales y digitales, asi como también herramientas y softwares gráficos para ejemplificación de tipologías. Esto, con el objeto de enriquecer la comunicación, expresión y comprensión de los conceptos expuestos, y también, para reflexionar sobre los procesos implicados en el acto de dibujar en formatos diferentes.

Nos referiremos al dibujo a mano alzada como un proceso por capas, planteando el asunto en tanto práctica reflexiva que se desarrolla buscando y estudiando producir el encuentro con la imagen (en un sentido técnico heideggeriano). Así, el esquema descriptivo que proponemos constituiría una capa de comprensión para tener en cuenta mientras se dibuja, y no necesariamente a modo de andamiaje constructivo ubicado por debajo o en la base del desarrollo temporal de un dibujar. Puede serlo y constituir un esquema de origen o modelo gráfico que facilite el juego y la exploración de alternativas para la posición del cuerpo humano en el espacio (tal y como se puede apreciar en algunos dibujos realizados para este texto). En cuyo caso, esperamos no bloqueen la búsqueda expresiva, sino que su aplicación permita al dibujante alteraciones y adaptaciones para el sistema volumétrico propuesto. Para lo cual, los volúmenes no debiesen considerarse rigurosamente 
regulares como los que ilustran las posibilidades en rotación a partir de cubos y cilindro sujetos a la perspectiva instrumental realizada en Adobe Illustrator. Por ejemplo, vemos que, en los dibujos a mano alzada realizados, los volúmenes cúbicos se transformaron más bien en paralelepípedos tipo caja. Por lo tanto, las bases inferior y superior en el cilindro definido para el Abdomen y sus conexiones con el Tórax y Caderas no podrían ser circulares -en escorzo, una elipse-, sino más bien de tipo oval. Siendo así, lo importante para la comprensión y aplicación del esquema en la zona Abdomen/Cilindro, será mantener la relación de perpendicularidad entre su eje y el eje mayor de la elipse/óvalo que conecta con el Tórax y Caderas. Pero, sobre todo, el esquema se valora por la posibilidad de apropiarse de una forma de visualización que simplifica la complejidad postural y gestual en la Figura Humana.

Volviendo sobre lo del dibujar como proceso que contiene capas, esta vez en softwares de dibujo, apreciamos la posibilidad que ofrecen los programas computacionales de dibujo CAD o editores de gráficos vectoriales (Adobe Illustrator) en términos de superponer información, apagando y encendiendo las capas de acuerdo a lo que se requiera en el proceso de representación y/o de presentación del diseño en sus diferentes etapas, pudiendo tipificar sus componentes y estudiar su valorización conforme a la proposición y expresión. Asunto que contribuye a ordenar la producción, a realizar cambios y por supuesto versiones, multiplicando así las posibilidades expresivas a través de la disponibilidad de su historial de producción. Por otro lado, en el programa Pages (Anotación Inteligente) que recientemente utilizamos en un Tablet, hemos podido experimentar en el proceso de dibujo las herramientas más simples de edición, tales como cortar, copiar, pegar, ir hacia adelante, ir hacia atrás, etcétera. Es decir, la posibilidad de realizar cambios respecto al historial inmediato del proceso, así como también hacer elecciones y cambios rápidamente en el ámbito de la virtualidad respecto del tipo de medio gráfico, color, grosor de línea y densidad del tinte. Sabemos de otros programas para dibujo digital a mano alzada con mayor rango de posibilidades para la expresión, que incorporan también las capas (por ejemplo SketchBook, que utilizamos para los dibujos de la imagen 10), pero se nos hace difícil acostumbrarnos al entorno virtual. Por ejemplo, al peso del lápiz que es uno y el mismo, o al desplazamiento de este sobre la pantalla, independiente del medio de expresión gráfico que se elija. Asuntos que, por otro lado, al aunar virtualmente los procedimientos y desagregar la edición favorecen la apariencia y presentación del dibujo, es decir, su resultado. Valoramos la posibilidad de hacer zoom in - zoom out y girar la imagen, y sobre todo, la capacidad del software para transmitir a la expresión del dibujo el factor de intensidad lineal producto de la presión que se ejerza. Pero nuestra experiencia hecha en falta la sensibilidad táctil entre la mano, el medio gráfico y el soporte, asunto que en la producción del dibujo posibilita una conexión entre el cuerpo, la mano y el medio, construyendo una duración sensible: la calidez del papel o su rugosidad; el peso y sensación de realidad del medio gráfico mientras lo desplazamos por el soporte producto de una decisión consciente o inconsciente de nuestra intencionalidad; o la incorporación del error como parte del proceso de estudio que permite poner especial atención en nuestros aciertos tanto como en nuestros fallos produciendo adaptaciones respecto de los objetivos que se tracen. En el entorno virtual sentimos la restricción del formato, cuyo tamaño permite dibujar con una movilidad reducida conteniendo la expresividad. Con la "pantalla" experimentamos un quiebre, una separación que mediatiza con "indiferencia" nuestra tactilidad.

\section{EL DIBUJO MEDIATIZADO, UNA FALACIA PEREZOSA.}

Pienso en la robótica, en la maquinización programada en una serie de instrucciones para la ejecución precisa de tareas altamente complejas que en la actualidad difieren de nuestras capacidades físicas. Si hiciéramos una comparación entre las facultades humanas asociadas a prácticas, reflexiones y técnicas artesanales respecto de las posibilidades y adelantos que la tecnología mediatizada ha impulsado en el área gráfica, ampliando a una velocidad sorprendente las fronteras para la producción, edición y representación gráfica, ¿qué motivación podría conducir a un dibujante a mano alzada a adoptar las innumerables ventajas de producción y edición que contienen los softwares de dibujo? Una respuesta posible ante este dilema -en tanto acto de Resistencia- me viene de la experiencia de dibujar in situ, atento a lo que acontece, consciente del proceso y su duración, desarrollando el dibujo para estudiar, para comprender el entorno, el alrededor, asumiendo el error como posibilidad atendible e incorporable. Por lo tanto, conectado, presente y atento a la interpretación y traducción analógica de la realidad a códigos gráficos tangibles. Es más, como una huella/registro de un dibujar cuya función es estudiar y comprender -más allá del resultado-, porque lo que desarrolla y contiene es justamente la búsqueda. Entonces diremos que, un dibujar para comprender se edita durante, no después (León, 2019); es un presente que se desarrolla y expresa desde una individualidad.

Inmerso en este contexto, el Dibujante consciente dibuja para comprender la figura humana en el espacio, confronta la realidad y la hace suya, mirada que lo pone en situación y lo hace partícipe de lo que construye y vivencia. ¿Será que el dibujo así mirado le permita al dibujante participar de modo mas activo en la Realidad? ¿Podría ser que una mirada reflexiva al acto de dibujar, en tanto proceso para la comprensión, nos acerque a una realidad concreta que facilite nuestra participación corporal en el mundo circundante? Este ir y venir en torno a la conceptualización de la Figura Humana y su forma de representarla en los tiempos de hoy, supone también una reflexión actual en torno al sentido del Dibujo para el hombre y la mirada sobre si mismo en el espacio, su percepción e inmersión en la realidad tangible. 


\section{BibLIOgRAFÍA}

Bachelard, Gastón (1978). La Dialéctica de la duración. Trad. Rosa Aguilar. Madrid, Villalar.

Barcsay, Jeno (1953). Anatomy for the Artist. Bekescsaba: Corvina.

Berry, William A (1994). Drawing the Human Form : Methods, Sources, Concepts. 2.nd ed. Upper Saddle River, N.J: Prentice Hall.

Bordes, JuAn (2003). Historia De Las Teorías De La Figura Humana: El Dibujo, La Anatomía, La Proporción, La Fisiognomía. Madrid: Cátedra.

Borges Soto, Roland (2016). Aprende a Dibujar El Cuerpo Humano.

Brambilla, Daniela (2015). Dibujo De La Figura Humana: Gestos, Posturas y Movimientos.

Deleuze, Gilles (1981). Empirismo y subjetividad. Trad. Hugo Acevedo. Barcelona, Gedisa.

Goldstein, Nathan (1981). Figure Drawing: The Structure, Anatomy, and Expressive Design of Human Form. 2nd ed. Englewood Cliffs, N. J: Prentice Hall.

GombRICH, E. H (1998). Arte e ilusión: estudio sobre la psicología de la representación pictórica. Madrid, Debate.

Hogarth, Burne (1990). Dynamic Anatomy. New York: Watson-Guptill Publications.

León luque, José Ignacio, Roy Dolcet, Josep, and Universitat De Barcelona (2019). Facultat De Belles Arts. Recorrido Y Conquista. Registros De Una Experiencia Extranjera En La Ciudad De Barcelona, 2016-2018. Universitat De Barcelona. Web.

MASLEn, M., Southern, J. (2011). Drawing Project: An Exploration of the Language of Drawing. London, Black Dog.

Marsh, Reginald (1970). Anatomy for Artists. New York: Dover Publications.

Parramón, José M (1973). Cómo Dibujar La Figura Humana. 7a ed. Barcelona: Instituto Parramón.

Smith, Stan (1985). Anatomía, Perspectiva Y Composición Para El Artista. Madrid: Blume.

Thomae, Reiner (1979). Perspectiva Y Axonometría. México Santiago, Chile: Gili. 